\title{
Agathisflavone modulates astrocytic responses and increases the population of neurons in an in vitro model of traumatic brain injury
}

Vanessa Cristina Meira de Amorim¹; Markley Silva Oliveira Júnior ${ }^{1}$; Alessandra Bispo da Silva1', Jorge M. David², Juceni Pereira Lima David³, Maria de Fátima Dias Costa $^{1}$, Arthur Morgan Butt ${ }^{4}$, Victor Diogenes Amaral da Silva ${ }^{1}$; Silvia Lima Costa ${ }^{1 *}$

1Department of Biochemistry and Biophysics, Institute of Health Sciences, Federal University of Bahia, Av. Reitor Miguel Calmon, Salvador-BA, 40100-902, Brazil; INCT/CNPq for Excitotoxicity and Neuroprotection; 'Department of General and Inorganic Chemistry, Institute of Chemistry, Federal University of Bahia, R. Barão de Jeremoabo, Salvador - BA, 40170-115,Brazil; ${ }^{3}$ Department of Medication, Faculty of Pharmacy, University Federal of Bahia, R. Barão de Jeremoabo, Salvador - BA, 40170-115, Brazil; ${ }^{4}$ School of Pharmacy and Biomedical Science, University of Portsmouth, Winston Churchill Avenue, Portsmouth PO1 2UP, United Kingdom.

*Corresponding author, Professor Silvia Lima Costa: Instituto de Ciências da Saúde Av. Reitor Miguel Calmon s/nº Vale do Canela, Salvador-Bahia, 40110-902, Brazil. Tel.: 55713283 8919; fax: +55 713283 8927. E-mail address: costasl@ufba.br

\section{Competing interests}

The authors declare no competing interests.

\begin{abstract}
Traumatic brain injury (TBI) is a critical health problem worldwide, with a high incidence rate and potentially severe long-term consequences. Depending on the level of mechanical stress, astrocytes react with complex morphological and functional changes known as reactive astrogliosis. In cases of severe tissue injury, astrocytes proliferate in the area immediately adjacent to the lesion to form the glial scar, which is a major barrier to neuronal regeneration in the central nervous system. The flavonoid agathisflavone has been shown to have neuroprotective, neurogenic and immunomodulatory effects, and could have beneficial effects in situations of TBI. In this study we investigated the effects of agathisflavone on modulating the responses of
\end{abstract}


astrocytes and neurons to injury, using the in vitro scratch wound model of TBI in primary cultures of rat cerebral cortex. In control conditions, the scratch wound induced an astroglial injury response, characterized by upregulation of glial fibrillary acidic protein (GFAP) and hypertrophy, together with reduction in proportion of neurons within the lesion site. Treatment with agathisflavone $(1 \mu \mathrm{M})$ decreased astroglial GFAP expression and hypertrophy and induced an increase in the number of neurons and neurite outgrowth into the lesion site. Agathisflavone also induced increased expression of the neurotrophic factors NGF and GDNF, which are associated with the neuroprotective profile of glial cells. These results demonstrate that in an in vitro model of TBI the flavonoid agathisflavone modulates the astrocytic injury response and glial scar formation, stimulating neural recomposition.

Keywords: Flavonoids, agathisflavone, 6,8"-Bisapigenin, NGF, GDNF.

\section{Introduction}

Traumatic brain injury (TBI) is critical health problem worldwide, with a high incidence rate and potentially severe long-term consequences (Langlois et al., 2006; Helmy et al., 2011; Thurman et al., 2016). In addition to the injuries caused directly by trauma, TBI has been associated with secondary neurological complications, such as post-traumatic stress disorder, memory deficits, chronic neuroinflammation, depression, post-traumatic epilepsy and dementia (Simon et al., 2017). The development of drugs that can reduce the damage caused by $\mathrm{TBI}$ and promote recovery is therefore of great importance (Diaz-Arrastia et al., 2014).

Astrocytes react to injury of the central nervous system (CNS) with complex changes in phenotype and function, known as reactive astrogliosis, depending on the severity of the stress to which they are subjected. Reactive astrocytes can assume different characteristics depending on blood brain barrier disruption, the degeneration of axons and local synapses, as well as a possible exposure to pathogens. In turn, reactive astrocytes influence neuroinflammatory responses and mechanisms of secondary injury in TBI. In cases of mild to moderate damage, astrocytes assume a hypertrophic 
morphology and, together with viable neural cells, persist in areas of damaged but functional neural tissue. In cases of severe tissue damage, astrocytes proliferate in the area immediately adjacent to the lesion and intertwine, forming the glial scar that surrounds and restricts the propagation of the intense inflammatory response in the center of the lesion (Burda et al, 2016; Costa et. al., 2002; Lefrançois, T. et al., 1997). These scar-forming astrocytes are present in areas that contain few or no surviving neural cells, interacting primarily with non-neural cells (Wanner et al., 2013). Although astrocyte scar formation aids central nervous system axon regeneration after the initial damage of the TBI (for review see Anderson et al., 2016), it also interferes with the subsequent regeneration of the CNS, inhibiting axonal regeneration (Barreto et al., 2011). In TBI, reactive astrocytes are characterized by increased expression of vimentin and glial fibrillary acidic protein (GFAP), proteins of the intermediate filaments. Knockout mice that do not express these proteins demonstrate deficient astrogliosis when subjected to $\mathrm{TBI}$, with less removal of cellular debris from the injured area and chronic dysfunction of the blood-brain barrier (Pekny et al., 1999), reinforcing the role of astrocytes response in TBI.

There is considerable interest in discovering new drugs that could modulate the deleterious effects of TBI-induced astrogliosis and inflammation on the CNS, so that they generate beneficial effects (Di Giovanni et al. al., 2005). Similarly, it is also important to develop drugs that can stimulate neurogenesis, repopulate the injured area with neurons and establish new neuronal connections (Armstrong et al., 2016). Flavonoids, which are polyphenolic compounds present in a wide variety of plants, have gained prominence as promising therapeutic alternatives for the treatment of CNS pathologies such as TBI (Macready et al., 2014), because of their anti-inflammatory (García-Lafuente et al., 2009), antioxidant (Zhang et al., 2016) and immunomodulatory (Peluso et al., 2015) capabilities. In addition, some flavonoids have proven to be able to cross the blood-brain barrier ( $\mathrm{Wu}$ et al., 2012). One promising compound is the biflavonoid agathisflavone, derived from the plant Poincianella pyramidalis Tull, botanical synonym for Caesalpinia pyramidalis, popularly known as Catingueira, an endemic tree from Northeastern Brazil adopted in popular medicine (Bahia et al., 2005; Agra et al., 2005; Diniz et al., 2015). Agathisflavone has demonstrated promising in vitro 
effects, including antiviral (Lin et al., 1997; De Souza et al., 2015a), anti-protozoal (De Souza et al., 2015b), anti-inflammatory (Velagapudi et al., 2018) and antitumor (Konan et al., 2012, Taiwo et al., 2017). It also induced neuronal differentiation and neurogenesis (Paulsen et al., 2011; Dos Santos Souza et al., 2018), as well as neuroprotection against glutamate-induced excitotoxicity (Dos Santos Souza et al., 2018; for a review see Amorim et al., 2018). In this context, the present study investigated the effect of the flavonoid agathisflavone on the modulation of the astroglial response and integrity of neurons in an in vitro model of TBI.

\section{Methods}

\section{Cerebral Cortex Primary Cultures}

Cell cultures were prepared from the cerebral cortex of Wistar rat embryos, obtained from the Center for Laboratory Animal Breeding of the School of Veterinary Medicine and Zootechnology of the Federal University of Bahia (Salvador, BA, Brazil). All experiments were performed in accordance with the local Ethical Committee for Animal Experimentation of the Health Sciences Institute (protocol № 027/2012). Cerebral Cortex Primary Cultures were prepared from E17/18 wild-type FVB/N mouse embryos according with protocols of Weber et al. (2012), with adaptations. The females were euthanized in a $\mathrm{CO}_{2}$ chamber and the gravid uteri were removed and placed in a Petri dish containing DMEM/HAM-F12 medium (GIBCO: REF 12500-039) supplemented with HEPES $(3.6 \mathrm{~g} / \mathrm{L}), 50 \%$ glucose $(100 \mathrm{IU} / \mathrm{mL})$, streptomycin $(100 \mu \mathrm{g} / \mathrm{mL})$ and sodium bicarbonate $(2.438 \mathrm{~g} / \mathrm{L})$. The embryos were removed from the uterus, transferred to another plate containing the same medium and decapitated. The cerebral cortices were isolated and their meninges were mechanically removed. The cortices were then mechanically dissociated with a Pasteur pipette and the cell suspension was gently forced through a sterile 75- $\mu \mathrm{m}$ Nitex Cell Strainer (Falcon, Brand-352360). Afterwards, the cells were centrifuged for $5 \mathrm{~min}$ at 1,000×g, the supernatant was discarded, and the cells were resuspended in fresh medium and counted in a Neubauer's Chamber. For experiments, cortical cells were resuspended in the abovementioned medium supplemented with $10 \%$ fetal bovine serum (Gibco-12657) and cultured in polystyrene 
culture plates of 24 wells or $60 \mathrm{~mm}$ in diameter (TPP, Trasadingen, Switzerland) precoated with Poly-L-ornithine $50 \mu \mathrm{g} / \mathrm{mL}$ (Sigma-ref: P3655), at a density of $2 \times 10^{5}$ cells $/ \mathrm{cm}^{2}$ and cultured for 10 days in a humidified atmosphere with $5 \% \mathrm{CO}_{2}$ and $37^{\circ} \mathrm{C}$. The medium of cortical cells cultures was changed every two days, and cells were cultured for 10 days (Fig. 1). At the time of experiments cortical cell cultures were composed of approximately $13 \%$ neurons and $67 \%$ astrocytes as determined by immunocytochemistry as described below. Three independent experiments were carried out for the different analysis.

\section{Flavonoid, scratch-wound and treatments}

Agathisflavone was extracted from the aqueous extract of the leaves of $P$. pyramidalis Tull as previously described (Mendes et al., 2000; Bahia et al., 2005; Bahia et al 2010). Briefly, fresh leaves $(2.2 \mathrm{~kg})$ of $P$. pyramidalis was extracted with methanol and chromatographed using silica gel to afford an enriched fraction of agathisflavone. Four grams of biflavonoid were isolated from fractions eluted with ethyl acetate: methanol $(8: 2)$ and recrystallized from methanol: hexane (1:1). The biflavonoid and its purity was carried on by $13 \mathrm{C}$ NMR, MS, and comparison with literature data [1, 2]. The a purity grade $>99.5 \% \mathrm{w} / \mathrm{w}$ as determined by DAD HPLC analysis at two wavelengths (254 and $283 \mathrm{~nm}$ ) and the relation of peak/noise of NMR spectra. Agathisflavone (FAB). Pale yellow power; m.p. 310-311 oC. APCIMS m/z 537.6 (negative mode); 13C NMR [75 MHz, (CD3)2CO, d (ppm)]: 163.9 (C-2), 103.3 (C-3), 182.3 (C-4), 159.7 (C-5), 103.6 (C6), 163.7 (C-7), 94.1 (C-8), 157.0 (C-9), 103.8 (C-10), 121.5 (C-1'), 128.6 (C-2'), 116.3 (C-3'), 161.3 (C-4'), 116.3 (C-5'), 128.6 (C-6'), 163.8 (C-2"), 102.7 (C-3"), 181.8 (C-4"), 160.6 (C-5"), 99.2 (C-6"), 163.6 (C-7"), 99.9 (C-8"), 155.1 (C-9"), 104.1 (C-10"), 121.6 (C-1"'), 128.2 (C-2"'), 116.2 (C-3"'), 161.2 (C-4"'), 116.2 (C-5"') and 128.2 (C-6"').

The isolated flavonoid was diluted in dimethyl sulfoxide (DMSO, Sigma) in stock solutions of $100 \mathrm{mM}$ that were stored protected from light at $-4^{\circ} \mathrm{C}$. Final concentrations of agathisflavone $(0.1$ and $1 \mu \mathrm{M})$ were obtained at the time of the treatment with the 
direct dilution of the flavonoid in the culture medium. For the experiments, cultures were pre-treated ( $1 \mathrm{~h}$ before injury) with DMSO $0.01 \%$ (control) or with agathisflavone $(0.1$ and/or $1 \mu \mathrm{M}$ ). Then, they were submitted to a mechanical lesion consisting of a $15-\mathrm{mm}$ trace made with a sterile polystyrene tip of $200-\mu \mathrm{L}$ capacity. After $48 \mathrm{~h}$, the cells were processed for immunocytochemical labeling of glia and neuron cytoskeletal proteins, western blot and gene expression analysis.

\section{Cell population analysis, neuronal integrity and glial response}

Neuronal integrity and glial response were assessed by immunocytochemical labeling for the $\beta$ - tubulin III ( $\beta$-TubIII), structural marker of neurons; for the glial fibrillary acidic protein (GFAP), structural marker of astrocytes. For both, cells were seeded in 24-well plates with glass coverslips previously treated with poly-L-ornithine $(50 \mu \mathrm{g} / \mathrm{mL})$. After treatments, the cultures were washed three times with PBS at pH 7.4 and fixed with $4 \%$ buffered paraformaldehyde for $20 \mathrm{~min}$ at $24^{\circ} \mathrm{C}$. Excess of paraformaldehyde was discarded and the plates were washed three times with PBS. At the time of the immunocytochemistry labeling, the cells were permeabilized with PBS/Triton X-100 $(0.2 \%)$ and blocked with bovine serum albumin BSA $(5 \%)$ in PBS for $1 \mathrm{~h}$. The cultures were then incubated separately for $12 \mathrm{~h}$ in a humid chamber at $4^{\circ} \mathrm{C}$ with PBS/BSA (1\%) solution containing mouse monoclonal antibodies specific for $\beta$-Tublll (1:500, Abcam AB78078), and rabbit polyclonal antibodies specific for GFAP (1: 500, Wako - G9269). After the incubation time, the excess of primary antibodies was removed, the cultures were washed three times with PBS and then incubated with goat secondary antibodies for rabbit IgGs or mouse IgGs conjugated with Alexa Fluor 488 or Alexa Fluor 594, diluted in 1\% PBS/BSA $(1: 1,000)$, and kept under slow agitation for $2 \mathrm{~h}$ at $24^{\circ} \mathrm{C}$. Next, for the detection of nuclear chromatin, the cultures were stained with the fluorescent DNA intercalating agent 4',6-diamidino-2-phenilindol dihydrochloride (DAPI, Molecular Probes, Eugene, OR) in a concentration of $5 \mu \mathrm{g} / \mathrm{mL}$, for $10 \mathrm{~min}$ at $24^{\circ} \mathrm{C}$. After that, the cultures were washed three times in PBS and mounted on slides with N-propyl gallate, and then observed under a Leica DM IL LED fluorescence microscope, with a suitable filter for fluorescence of the secondary antibodies. This assay was performed in three 
independent cultures. For cell counts in the lesion site, eight representative fields were photographed at 20x magnification, and the area of the lesion was reconstituted from one edge to the other of the lesion. Images were captured with either a 40x objective or a 63x oil immersion objective using a Leica TCS SP8 Spectral Confocal Microscope for more detailed photos. All experiments included cultures where the primary antibodies were not added, unspecific staining was not observed in such negative controls.

\section{RNA extraction and qPCR}

Total RNA was isolated from embryonic cerebral cortex cell cultures with the Trizol reagent (Ambiom 15596018) according to the manufacturer's specifications. For that, $7 \times 10^{4}$ cells $/ \mathrm{cm}^{2}$ were grown in $60-\mathrm{mm}$ plates and treated; the samples were stored at $80^{\circ} \mathrm{C}$ until the time of the analysis. Both the concentration and the purity of the RNA were determined with spectrophotometric analysis using the Kasvi nanospectrum (K230002). DNA contaminants were removed with the treatment of DNase RNA samples using the Ambion DNA-free kit cat \# AM1906 (Life Technologies ${ }^{\mathrm{TM}}$ ). For cDNA synthesis, VILO ${ }^{\mathrm{TM}}$ cat \# MAN0004286 (Invitrogen, Life Technologies ${ }^{\mathrm{TM}}$ ) Master Mix Super Script ${ }^{\circledR}$ was used in a $20-\mu \mathrm{L}$ reaction with a concentration of up to $2.5 \mu \mathrm{g}$ of total RNA. Real-time quantitative PCR was performed using Taqman ${ }^{\circledR}$ Gene Expression Assays (Applied Biosystems, CA, USA) containing two primers to amplify the Taqman $\circledast$ MGB and Taqman $\circledast$ MGB specific probe sequence and TaqMan $\circledast$ Universal Master Mix II with UNG (Catalog \# 4440038 Invitrogen, Life Technologies ${ }^{\mathrm{TM}}$ ). Assays for the genes quantified in this study were: NGF (Rn01533872_m1) and GDNF (Rn00569510_m1). Real-time PCR was performed using the QuantStudio ${ }^{\text {TM }} 7$ Flex Real-Time PCR System (Applied Biosystems, CA, USA). The thermocycling conditions were performed according to the manufacturer's specifications. The $\beta$-actin target (Rn00667869_m1) was used as the reference gene (endogenous control) for normalizing gene expression data. The analysis of real-time polymerase chain reaction data was based on Schmittgen and Livak (2008), using the 2- $\Delta \Delta \mathrm{Ct}$ method. Tests were performed in triplicate in different plates of each cDNA using different samples were analyzed and values were averaged for each mRNA. 


\section{Western Blot}

After treatment, cultures of embryonic cortex were collected, lysis buffer (4 M urea, 2\% SDS, $2 \mathrm{mM}$ ethylene glycol-bis( $\beta$-aminoethyl ether)- $\mathrm{N}, \mathrm{N}, \mathrm{N}^{\prime}, \mathrm{N}^{\prime}$-tetraacetic acid (EGTA), $62.5 \mathrm{mM}$ Tris-HCl pH 6.8, 2 mM ethylenediaminetetraacetic acid (EDTA), 0.5\% Triton X100 ) supplemented with protease inhibitor cocktail (Sigma-Aldrich, P8340) was added and the total proteins were extracted. Five micrograms of protein per column were separated by electrophoresis on $12 \%$ polyacrylamide gel. After separation, the proteins were transferred to a polyvinylidene fluoride (PVDF) membrane (Hybond, Amersham, Piscataway, USA) in a semi-dry system (Bio-Rad, Hercules, USA) for $120 \mathrm{~min}$ at a constant current of $0.15 \mathrm{~mA}$. The membranes were blocked with $5 \%$ skimmed milk diluted in Tris-buffered saline (TBS) containing $0.05 \%$ Tween-20 (TBS-T) at room temperature under stirring. After blocking, the membranes were incubated with antiGFAP (rabbit, 1: 1,000, DAKO Z0334) or anti- $\beta$-actin (rabbit, 1: 5,000, Sigma A5060) primary antibody overnight at $4^{\circ} \mathrm{C}$. The membranes were then washed three times with TBS-T and incubated for $1 \mathrm{~h}$ at room temperature on shaking with peroxidaseconjugated goat anti-rabbit secondary antibody (1: 5000; Molecular probes, G21234) diluted in TBS- T 5\% skimmed milk. After three washes with TBS-T and one wash with TBS, the membranes were incubated with the chemiluminescent reagents (ECL Plus substrate kit Biorad) for $5 \mathrm{~min}$. The blots were then analyzed by the ImageQuant LAS 500 apparatus (GE Healthcare Life Sciences). The value of each protein was normalized according to the amount of $\beta$-actin in the same sample. Quantification was obtained by scanning densitometry (ScanJet 4C, Hewlett Packard) of three independent experiments, and analyzed with ImageJ $1.33 \mathrm{u}$ software (Wayne Rasband, National Institutes of Health, USA).

\section{Statistical analyses}

Statistical analyses were performed using the GraphPad Prism 5.0 software (San Diego, CA, USA) for Windows. We used Student's t-test or one-way analysis of 
variance (ANOVA) when more than 2 groups were compared, followed by Student's Newmann-Keuls' post-test. The results were expressed as the mean \pm standard deviation of three independent experiments. Values of $p<0.05$ were considered as significant.

\section{Results}

Analysis of neuron integrity and astrocyte response

Figure 1 illustrates embryonic cortical cultures $48 \mathrm{~h}$ after a scratch wound under phase contrast microscopy. In control culture conditions (normal medium plus the drug vehicle $0.01 \%$ DMSO), cells are observed to extend few projections from the border of the lesion site and few cells are present within the lesion. In contrast, cultures treated with agathisflavone $(1 \mu \mathrm{M})$ displayed an increased number of cellular projections into the lesion site and a much larger number of cells in the lesioned area.
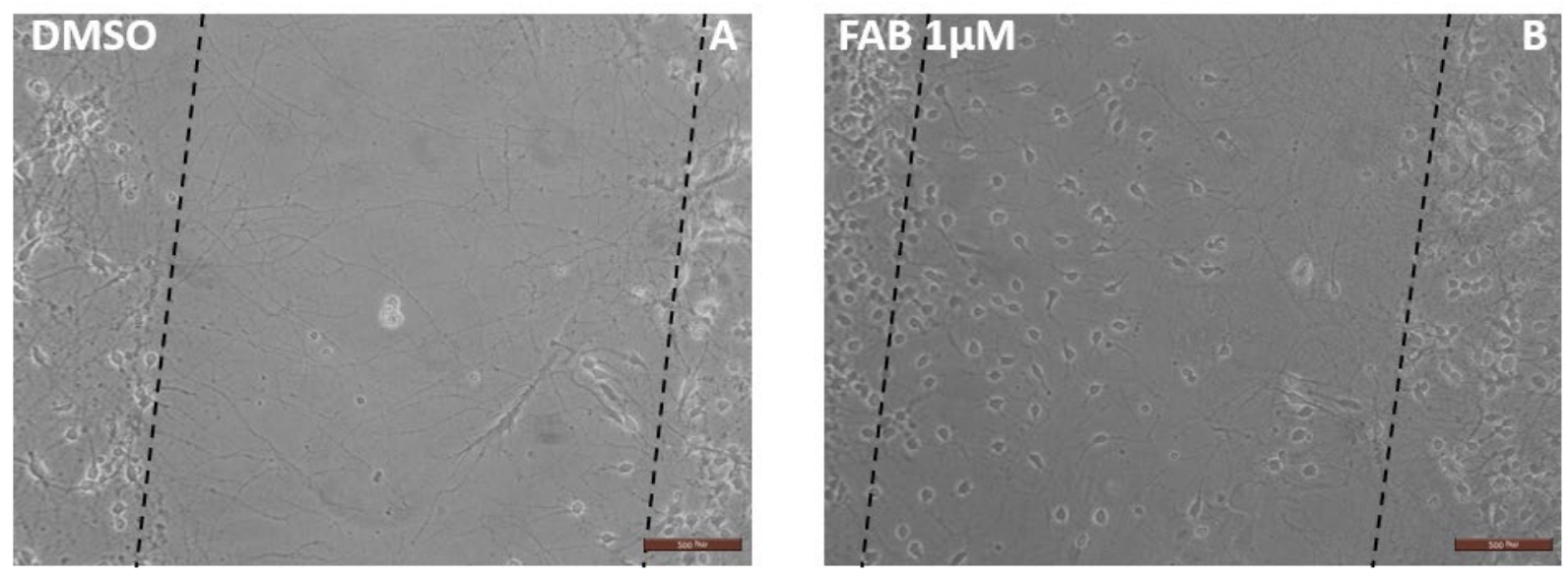

Figure 1 - Effect of the pre-treatment with agathisflavone (FAB) on the migration of cells and extension of projections to the site of mechanical injury in primary culture of embryonic cerebral cortex of rats. Phase contrast photomicrographies of cultures maintained in control conditions $(0.01 \%$ DMSO, A) or treated for $1 \mathrm{~h}$ with $1 \mu \mathrm{M}$ agathisflavone (B), submitted to injury and analyzed after 48 h. Obj. 10x. Scale bar 200 $\mu \mathrm{m}$. Dashed lines indicate the edges of the lesions. 
In order to characterize the glial and neuron cell profile in the lesion site under control conditions and after treatment with agathisflavone, two cytoskeletal markers were used, GFAP for astrocytes and $\beta$-tubulin III ( $\beta$-TubIII) for neurons in the cortical cultures, characterized of about $13 \%$ neurons and $67 \%$ astrocytes; nuclei of the cells were stained with DAPI, a nuclear chromatin intercalating agent (Fig. 2). In controls, injury induced astrogliosis, with increase of astrocyte processes associated with increased expression of GFAP, especially visible at the edges of the lesions, together with a reduction of neurites at the edge of the lesion, with decreased expression of $\beta$-TubllI. In the culture treated with agathisflavone $(1 \mu \mathrm{M})$, there was modulation of the astrocytic response, with a decrease of GFAP in astrocytic processes that invade the area of the lesion from the border, which are less thick, as well as an increase in neurons within the lesion and the growth of neurites that enter the lesion. It was possible to observe that neurite migrated along astrocytic bodies in the lesion zone, leading to the other edge of the lesion (Fig. 2, merged panels). 
CONTROL
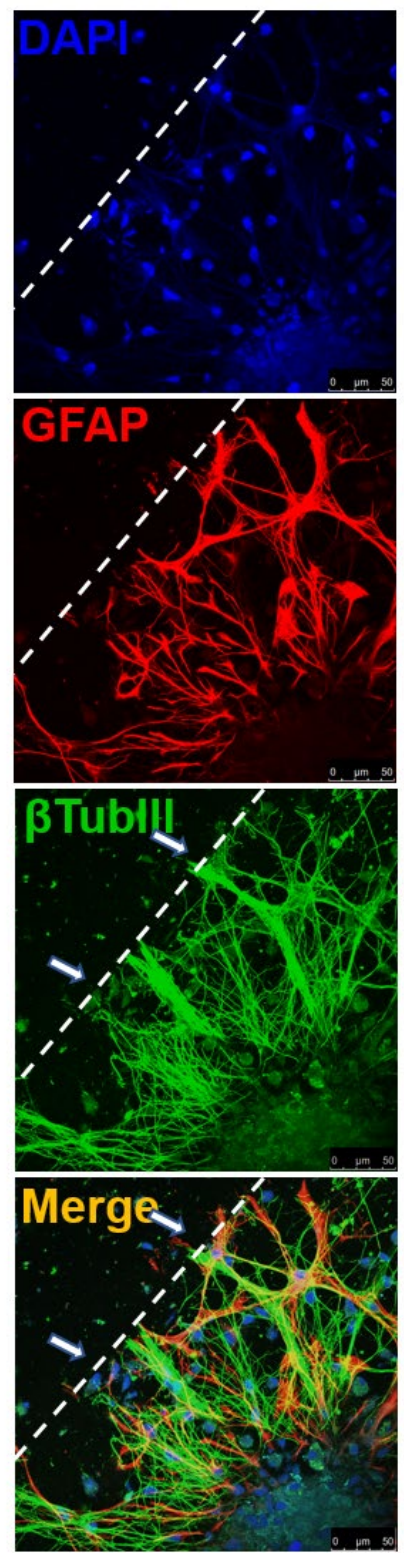

CONTROL
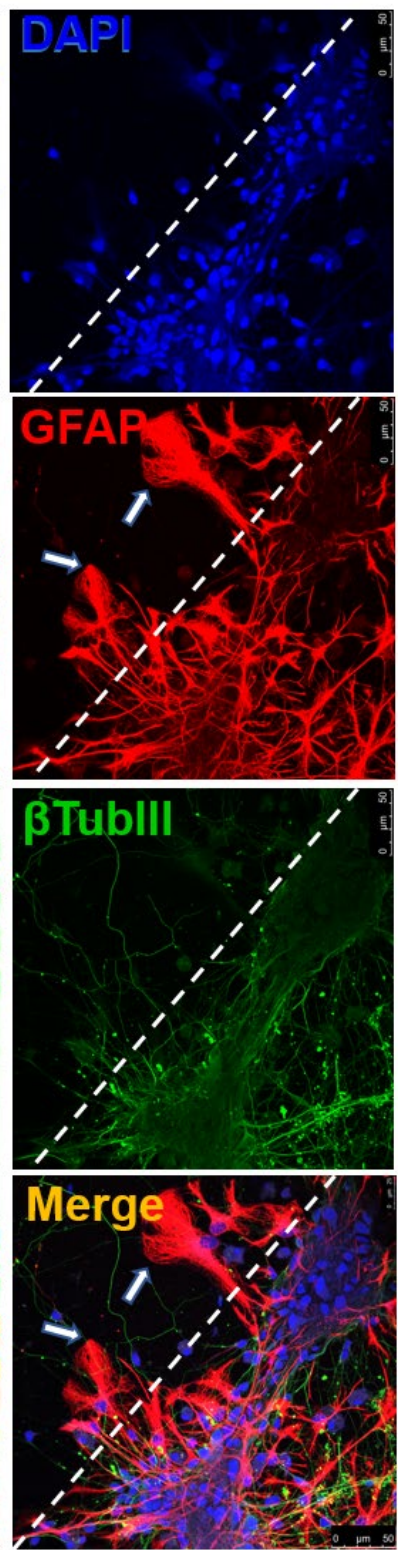

FAB $1 \mu M$
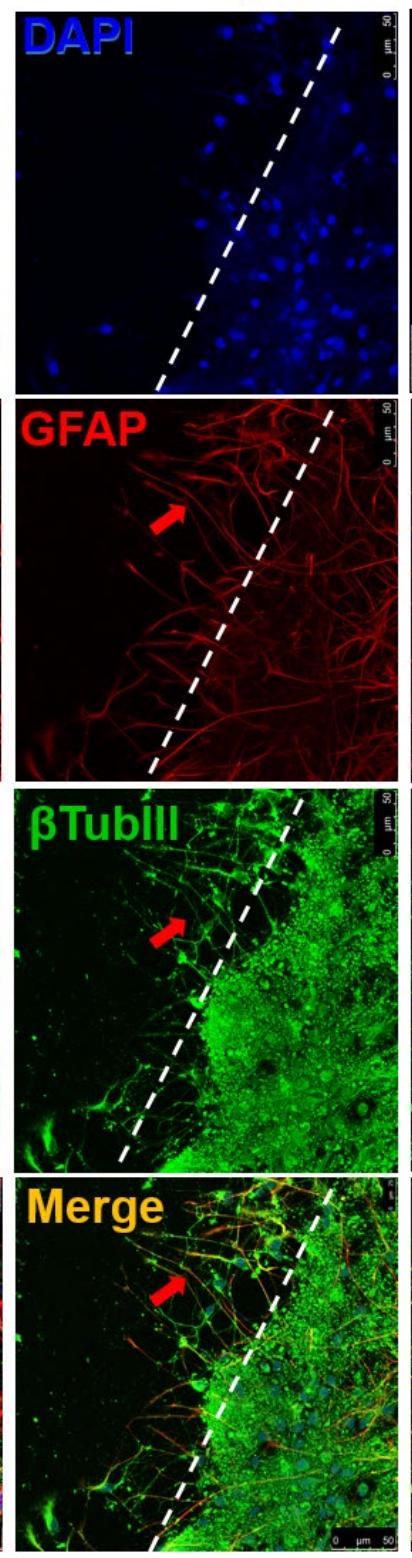

FAB $1 \mu \mathrm{M}$
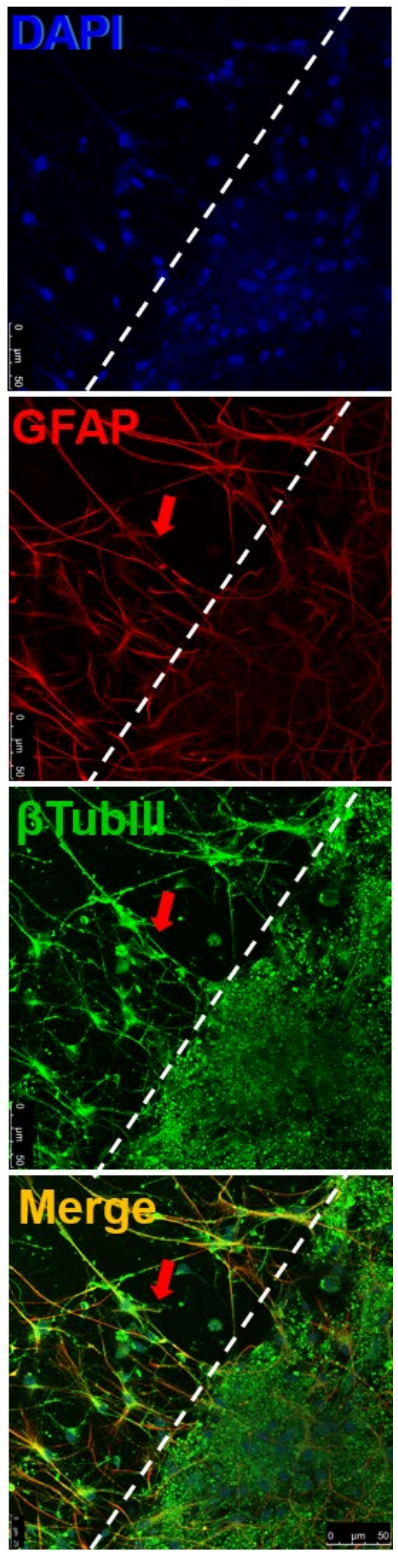

Figure 2 - Effect of the flavonoid agathisflavone (FAB) on the morphology and migratory behavior of neurons and astrocytes in primary culture of embryonic cerebral cortex of rats submitted to mechanical injury. Cultures were maintained in control conditions $(0.01 \%$ DMSO) or treated for $1 \mathrm{~h}$ with $1 \mu \mathrm{M}$ agathisflavone, submitted to injury and analyzed by Immunocytochemistry for GFAP (red) and $\beta$-tubulin III ( $\beta$ tubllI, Green); nuclei were stained with DAPI (Blue). Confocal photomicrographies of GFAP positive astrocyte and $\beta$-tublll positive neurons in the edge of the lesions; dashed lines indicate the edges of the lesions; Obj. 40x. Scale bar $50 \mu \mathrm{m}$. In lesioned cultures, reactive astrocytes with increased GFAP expression can be seen at the border of the lesion, as well as lesioned neurites (white arrows). Treatment with agathisflavone modulated the astrocytic response, with astrocytic processes invading the area of the lesion and inducing neurite outgrowth (red arrows). 
Quantification of cells that migrated to the lesion site revealed that in cultures treated with agathisflavone $(1 \mu \mathrm{M})$, there was a significant increase in the number of nuclei stained with DAPI in the lesioned area $(104.1 \pm 8.008)$ when compared to the control (DMSO $0.01 \%$ ) (38 \pm 6.728 ), indicating that flavonoid induced cells to migrate to the lesioned area (Fig. 3A). Treatment with agathisflavone also resulted in a significant increase in $\beta$-Tublll positive neurons $\left(\beta\right.$-TubllI ${ }^{+}$) in the lesion, from $1.03 \pm 0.67$ to 16.68 $\pm 1.30 \%$ (Fig. $3 \mathrm{~B}$ ), whereas $\mathrm{GFAP}^{+}$astrocytes were significantly reduced in the lesioned area, from $18.67 \pm 0.82 \%$ to $0.55 \pm 0.61 \%$ (Fig. $3 C$ ), as were the number of $\mathrm{GFAP}^{+}$ hypertrophic processes, from $28.00 \pm 2.65$ to $4.80 \pm 1.02$ (Fig. 3D).

A
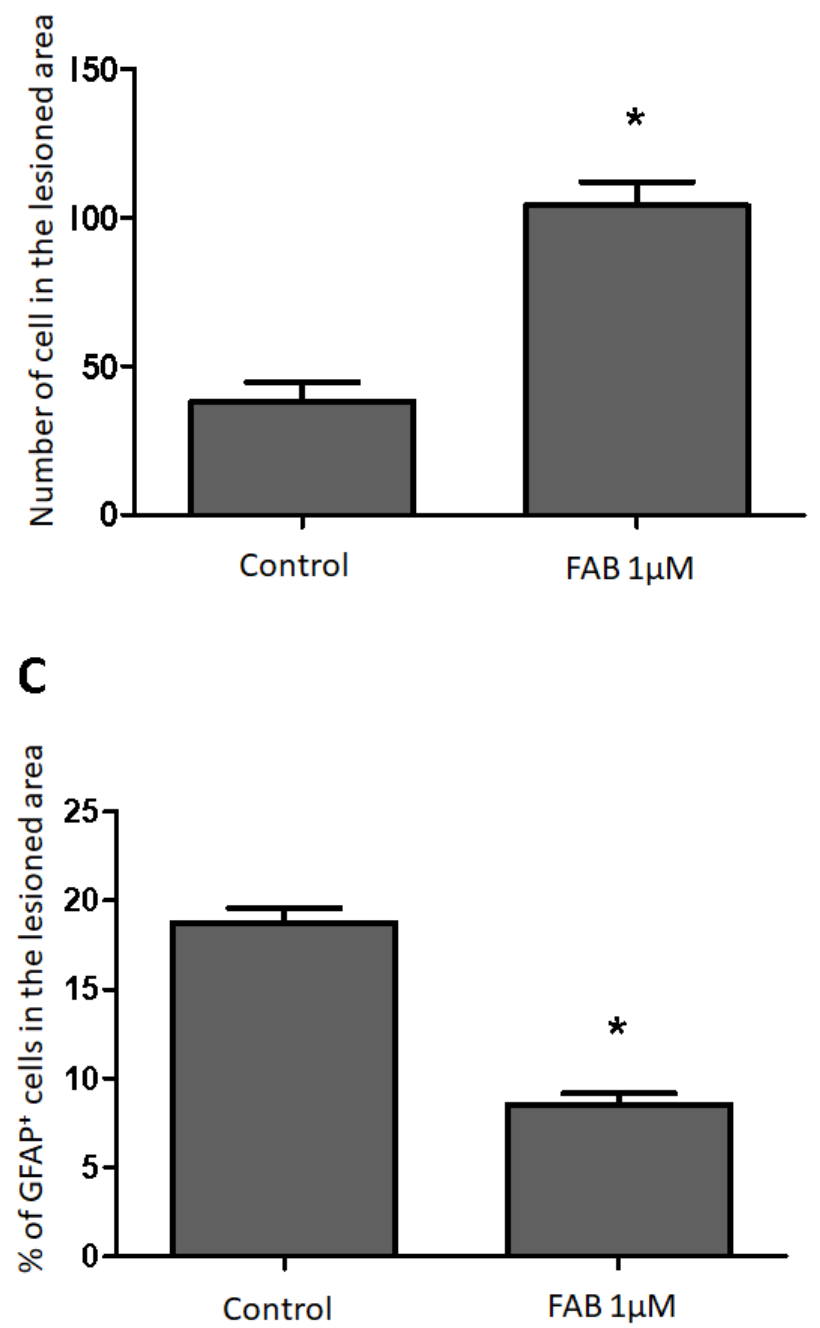

B
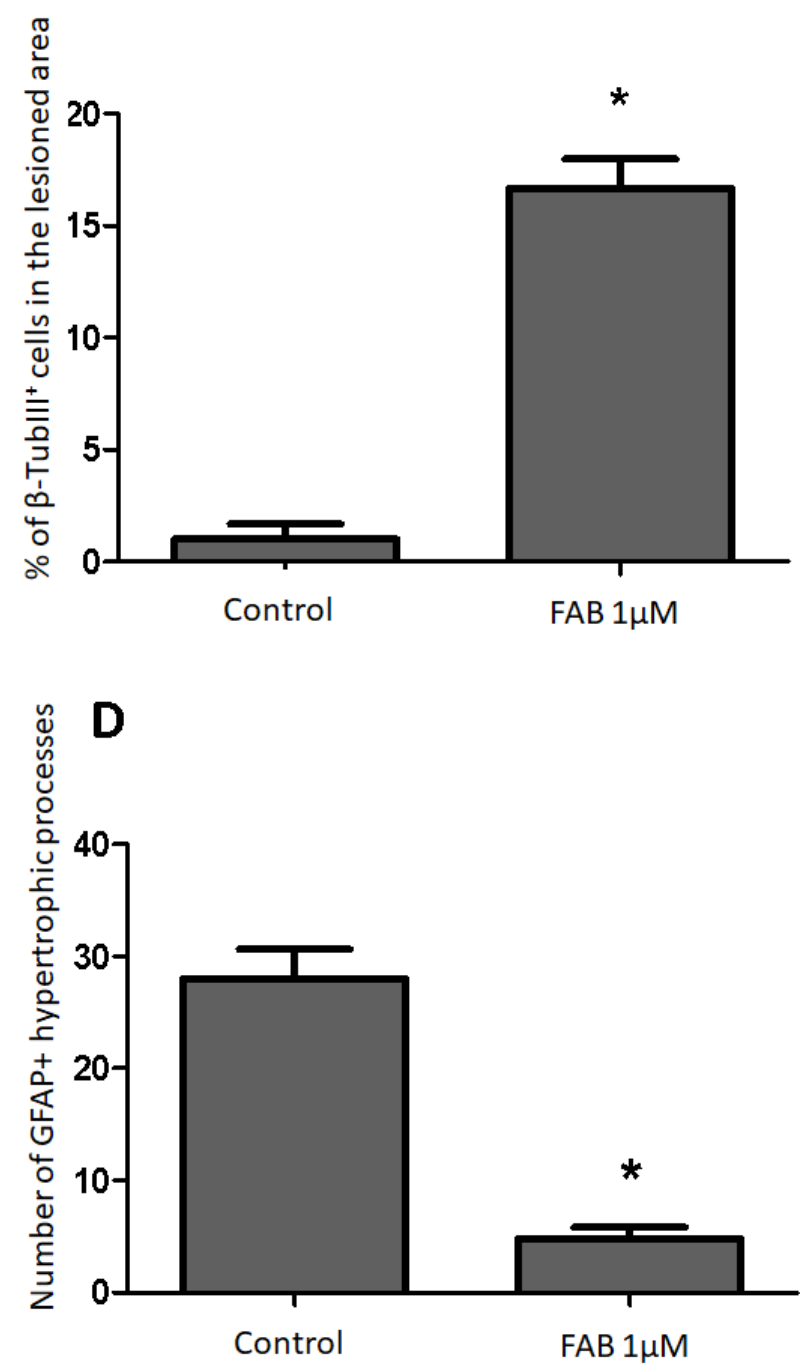
Figure 3 - Analysis of the effect of the flavonoid agathisflavone on the morphology and migratory behavior of astrocytes and neurons in primary culture derived from the embryonic cortex of rats submitted to mechanical injury. (A) Number of nuclei stained with DAPI in the lesioned area. (B) Percentage of $\beta$ - tubulin III ( $\beta$-tubllI) labeled cells in the lesioned area. (C) Percentage of GFAP-labeled cells (GFAP+) in the lesioned area. (D) Number of GFAP+ hypertrophic processes at the edge of the lesion. T- Test ${ }^{*} \mathrm{P}<0.05$.

In order to quantify changes in GFAP expression levels, western blot for GFAP was performed $48 \mathrm{~h}$ after scratch wound. Treatment with agathisflavone at $1 \mu \mathrm{M}$, which induced the morphological effects described above, induced a significant reduction in GFAP expression $(72.74 \pm 4.78 \%$ ), when compared to the control (considered $100 \%$ ) (Fig. 4); $0.1 \mu \mathrm{M}$ agathisflavone had no effect on GFAP expression compared to the control cultures.

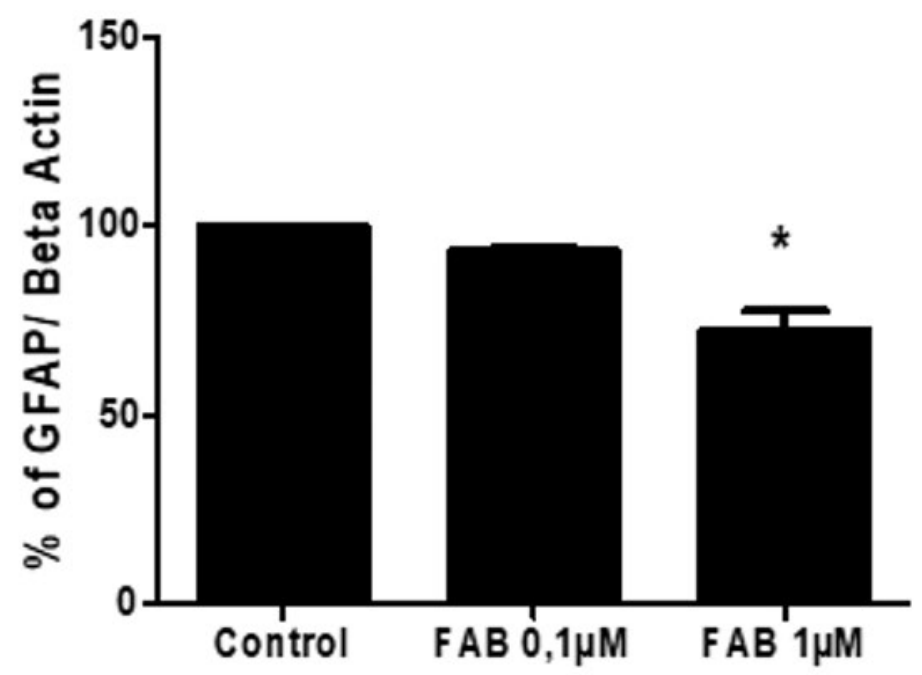

Control FAB $0,1 \mu \mathrm{M} \quad \mathrm{FAB} 1 \mu \mathrm{M}$

$50 \mathrm{kDa}$

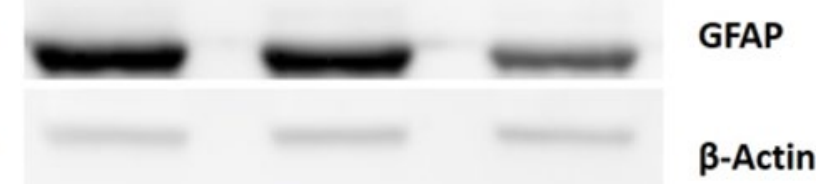

$42 \mathrm{kDa}$

$\beta$-Actin

Figure 4 - Effect of the flavonoid agathisflavone (FAB) on the expression of glial fibrillary acidic protein (GFAP) in primary culture of embryonic cerebral cortex of rats subjected to mechanical injury. Cultures were maintained in control conditions $(0.01 \% \mathrm{DMSO})$ or treated for $1 \mathrm{~h}$ with $1 \mu \mathrm{M}$ agathisflavone submitted to injury and 
analyzed after 48 h. (A) Western blot analysis for GFAP and $\beta$-actin. (B) Densitometry analysis of the ratio of GFAP/ $\beta$-actin expression; values expressed as mean \pm standard deviation and control was considered as $100 \%$; results were analyzed by One-way ANOVA followed by followed by Student's Newmann-Keuls' post-test; * P $\leq 0.05$. Experiment showed a decrease in GFAP expression in cultures treated with $1 \mu \mathrm{M} F A B$ and submitted to scratch injury, compared to control cultures.

\section{Effect of the treatment with the flavonoid agathisflavone on expression of neurotrophic factors}

To investigate the molecular mechanisms that could be involved in the observed effects of agathisflavone on increasing neurons and neurite outgrowth within the scratch lesion, we examined mRNA expression for the neurotrophins NGF and GDNF, using RT-qPCR (Fig. 5). In non-lesioned cultures, compared to non-lesioned control cultures, agathisflavone at the effective concentration of $1 \mu \mathrm{M}$ induced a 3.6-fold and 6.3-fold increase in NGF and GDNF mRNA expression, respectively. In contrast, $0.1 \mu \mathrm{M}$ agathisflavone induced a 2.4-fold increase in NGF mRNA expression and reduction of GDNF mRNA expression. Following scratch wound, compared to untreated control cultures, agathisflavone at the effective concentration of $1 \mu \mathrm{M}$ induced a 25 -fold and 8.3-fold increase of mRNA expression of NGF and GDNF, respectively. At $0.1 \mu \mathrm{M}$, agathisflavone induced a 2.5 -fold increase in NGF and GDNF mRNA expression. When lesioned and non-lesioned cultures under control conditions (DMSO 0.01\%) were compared, no difference between the levels of mRNA expression was observed for the either of the neurotrophins studied. 

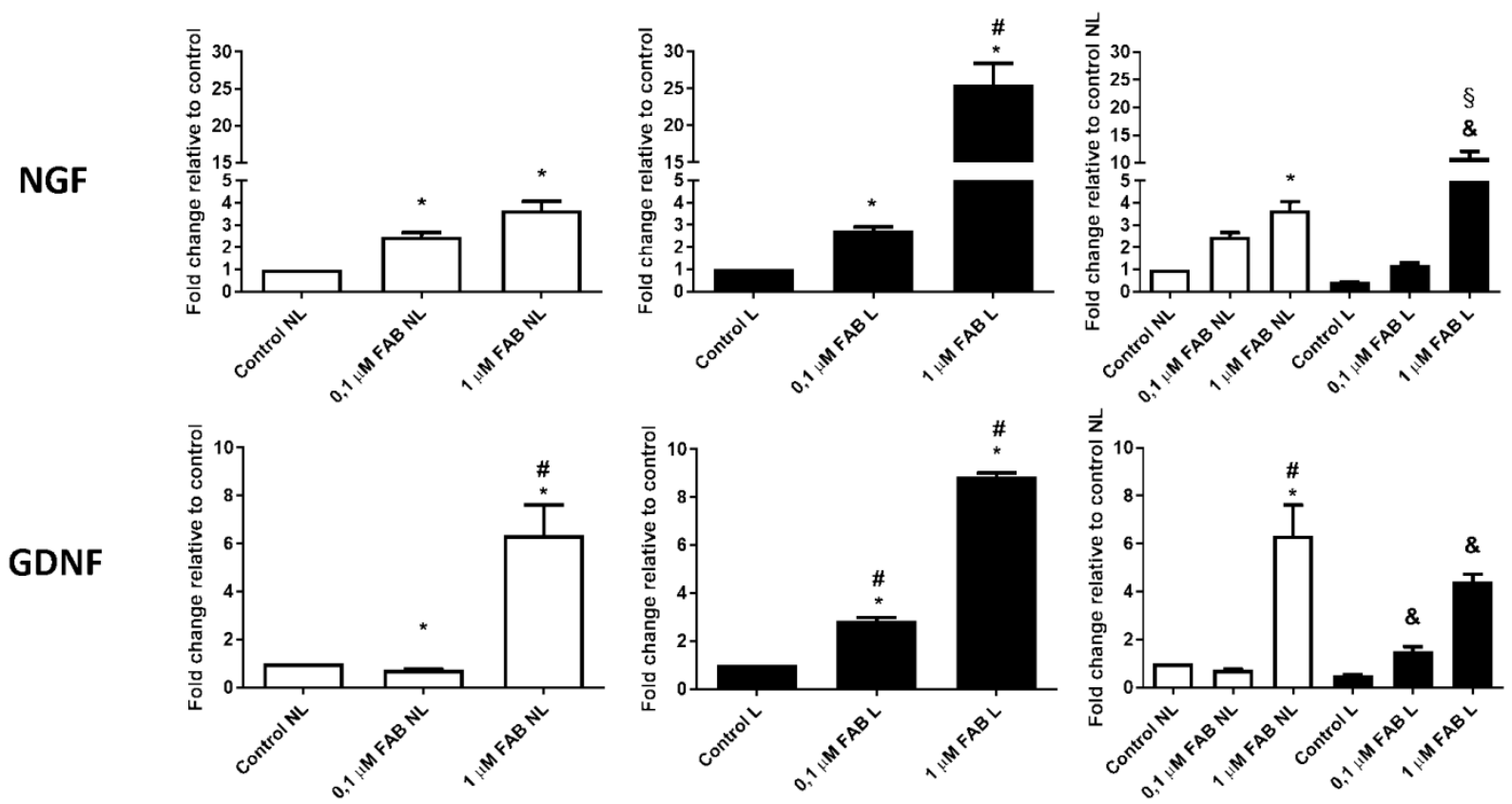

Figure 5 - Effect of the flavonoid agathisflavone on the expression of neurotrophic factors in primary culture of embryonic cerebral cortex of rats submitted or not to mechanical injury. Cultures were maintained in control conditions $(0.01 \% \mathrm{DMSO})$ or treated for $1 \mathrm{~h}$ with $1 \mu \mathrm{M}$ agathisflavone, injured and analyzed after $48 \mathrm{~h}$. Expression of mRNA for neurotrophic factors NGF and GFDN was analyzed with RT-qPCR; $\quad \mathrm{NL}=$ Non-lesioned; $\mathrm{L}=$ Lesioned; values expressed as mean \pm standard deviation; significant differences are expressed as ${ }^{*} \mathrm{P} \leq 0.05$ when compared to the control NL; \# P $\leq 0.05$ when compared to $F A B \quad 0.1 \mu \mathrm{M}$ NL treatment; \& $P \leq 0.05$ when compared to the Control L; and $\S P \leq 0.05$ when compared to $\mathrm{FAB} 0.1 \mu \mathrm{M} \mathrm{L}$ treatment. One-way ANOVA followed by Student's Newmann-Keuls' post-test. Agathisflavone increased the expression of GDNF and NGF in a dose-dependent manner in cultures submitted or not to injury.

\section{Discussion}

In vitro models for CNS injury are an important step in the development of new neuroprotective therapies. The model of mixed culture of cells from the embryonic cortex forms a confluent monolayer of glial cells that adheres to the plaque and allows the development of morphologically mature neurons on glia (Weber et al., 2012). In these cultures, the scratch-injury simulates aspects of damage caused by $\mathrm{TBI}$ in vitro 
(Han et al., 2014), which allows the evaluation of the effects of drugs such as the flavonoid agathisflavone on modulation of the astrocyte injury response and scar formation, integrity of neurons and restoration of neuronal projections. Although this flavonoid has already been tested for some pharmacological effects, such as increased induction of neurogenesis in association with retinoic acid (Paulsen et al., 2011), affinity for GABAergic receptors (Grosso et al., 2013) and neuroprotection (Dos Santos Souza et al. al., 2018), there is nothing on its effects on TBI models in the literature. Together, the results of this study show that the flavonoid agathisflavone modulates the astrocytic injury response and formation of glial scar, favoring the migration of neurons to the site of the lesion neurite outgrowth. These effects were associated with stimulation of NGF and GDNF, neurotrophins that are important for neuronal outgrowth.

Consistent with previous studies, we observed that the scratch wound caused a typical astrocyte injury response, with upregulation of GFAP and cellular hypertrophy at the lesion edge, similar to scar formation. Shi et al. (2015) observed morphological changes in GFAP expression by astrocytes in cultures after mechanical injury, with these cells having extended astrocytic processes to the cell-free area $12 \mathrm{~h}$ post-injury, which were shown to be more prominent after $24 \mathrm{~h}$. A similar behavior was also seen by Huang et al., (2009), with processes extending to the area of the injury $24 \mathrm{~h}$ after trauma. Katano et al. (1999) performed a mechanical lesion on astrocyte cultures and on glial and neuronal co-cultures and noted that the migration and extension of astrocyte projections after $24 \mathrm{~h}$ was much more intense in cultures with only glial cells compared to cocultures. In both cultures, astrogliosis was observed at the edges of the lesion, characterized by increased GFAP expression and astrocyte morphology change. Costa et al. (2002) reported that after mechanical injury, glia and neuronal co-cultures exhibit reactive and hypertrophic astrocytes at the edge of the lesion, forming a poorly permissive environment for neuronal migration or neurite outgrowth. They also reported that, by decreasing GFAP expression of injured astrocytes through the treatment with antisense GFAP-mRNA and association with the extracellular laminin matrix component, there was a decrease in astrocytic reactivity and a return of neuron migration and neurite outgrowth to the area of the lesion. The same profile of astrocytic response, characterized by the induction of astrogliosis and increase in the expression 
of GFAP after mechanical lesion, was observed in the present study, with the establishment of a glial scar that was not permissive for the migration of neurons or neurites to the lesioned area. Significantly, treatment with agathisflavone $(1 \mu \mathrm{M})$ led to a decrease in GFAP expression and astroglial scar formation, associated with increased neurite outgrowth towards the injured area and neuronal repopulation of the lesion site.

Previous studies on neural cell cultures (astrocytes, neurons and oligodendrocytes) derived from neural stem cells and subjected to mechanical injury (Lööv et al., 2012; 2013) observed that the neurons were attracted and migrate to the site of lesion in the process of regeneration, but they did not cross the edges of the lesion. Astrocytes were also attracted to the site of lesion, extending their processes beyond the edges towards the cell-free area. Surgucheva et al. (2014), in the same type of culture, also submitted to mechanical injury, reported a change in the morphology of the neurons next to the lesion, with loss of axons and fewer neurites, as well as the migration of a small number of neurons to the interior of the lesion after $48 \mathrm{~h}$. It was also shown that astrocytes extend their processes and migrate to the area of the lesion. Similar characteristics were observed in the present study, where control cultures presented the rupture and loss of neurites and axons in the lesioned area after $48 \mathrm{~h}$, and the migration of a small number of neurons that migrated into the lesion, associated with astrocytes that migrated and extended its hypertrophic processes to the injured area. However, in the cultures that were treated with the flavonoid agathisflavone and injured, modulation of the astrocyte response was observed, with decreased expression of GFAP and astrocytes with less reactive morphology, making the glial scar more permissive for migration and growth of neurons.

The effects of agathisflavone increasing the number of neuron bodies in the edge of the lesion and the neurons penetrating the lesioned area observed in this study were associated with the increase of NGF and GDNF. Neurons and glial cells secrete endogenous peptides called neurotrophins, which are important for the regulation of synaptic plasticity, the stimulation of neurogenesis and the protection of neurons against apoptosis (Kuipers et al., 2016; Wurzelmann et al., 2017). NGF is essential for the development and maintenance of cholinergic neurons in the CNS and can be produced 
far from its site of action and transported to neurons where it will promote survival, functional and developmental changes in these cells (Lane et al., 2014; Li et al., 2018). GDNF is known for its important role in neuronal survival and stimulus for axon growth, in addition to being associated with neuroprotection against metabolic and excitotoxic insults (Bankston et al., 2013; Cohen et al., 2011; Nagahara et al., 2009). In a previous study, developed in co-cultures of murine neurons and glia submitted to glutamate excitotoxicity, we demonstrated that agathisflavone was able to increase the expression of several neurotrophins, among them BDNF, NGF, CDNF, NT4 and GDNF. This increase in the expression of neurotrophins was associated with neuroprotection against glutamate excitotoxicity (Dos Santos Souza et al., 2018). Some of the important aspects in the pathology of the TBI are excitotoxicity by glutamate, the loss of neurons and neuronal extensions, as well as the formation of a glial scar that interferes in the regeneration of the CNS (Barretto et al., 2011; Johnson et al., 2013; Rosenfeld et al. al., 2012). Moreover, Paulsen et al. (2011) reported that, when used in combination with retinoic acid (RA) in embryonic stem cells and murine-induced pluripotent stem cells, agathisflavone increases RA-induced neuronal differentiation 2-fold or more in both cell types. Therefore, a drug such as agathisflavone, capable of interfering beneficially in all these aspects, is of great importance.

Phytoestrogens are compounds of plant origin that can mimic, structurally or functionally, mammalian estrogen. One example is the isoflavone genistein, whose activation of estrogen receptors is one of the mechanisms responsible for its osteoblastogenic effects (Cepeda et al., 2020). Another is apigenin, the monomer that forms agathisflavone, which is described as pro-estrogenic and acts as a phytoestrogen and / or estrogen receptor modulator (Zand et al., 2000). Agathisflavone itself has also been described as a phytoestrogen and its pro-neuronal effects are at least partially mediated by the activation of the estrogen receptors $\alpha$ and $\beta$ (Dos Santos Souza et al., 2018). Steroid hormones, including estrogen, can influence the development and function of the nervous system, affecting areas such as synaptic plasticity (Takeuchi et al., 2015) and cognitive function (Luine et al., 2014), as well as providing neuroprotective effects (Engler-Chiurazzi et al., 2016). However, the use of estrogenbased therapies is limited by the increased risk of estrogen-dependent tumors and 
cardiovascular problems. A possible solution would be to use substances that specifically modulate estrogen receptors to achieve the beneficial effects without the associated risks (Su et al., 2018) and it has been reported that agathisflavone interferes with neurogenesis and neuronal differentiation through the activation of estrogen receptors (ERa and ER $\beta$ ) (Dos Santos Souza et al., 2018). Moreover, toxicological evaluation of the biflavonoid agathisflavone showed LD50 larger than $2000 \mathrm{mg} / \mathrm{kg}$ and that it did not change significantly the hematological, biochemical, histopathological, behavioral, as well as physiological parameters in mice (Andrade et al., 2018). In this sense, agathisflavone could be a potential candidate as a phytoestrogen drug to attenuate astrogliosis and reestablish the population of neurons and neuronal connections in brain lesions such as TBI.

\section{Conclusion}

Our findings demonstrate that the flavonoid agathisflavone is capable of modulating astrocytic response and glial scar formation, while also stimulating neural network recomposition in an in vitro model of TBI, associated with the modulation of GDNF and NGF, making it a potential candidate for therapy.

\section{Acknowledgements}

This work was supported by the Coordination of Personnel Improvement of Higher Level (CAPES, PGCI - Process No 88881.117666/2016-01), Foundation for Research Support of the State of Bahia (Process N N INT 0016/2016), the National Council for Scientific and Technological Development (CNPq, MCTI/CNPq/Universal 14/2014 Process 443723/2014-1) and by the INCT/CNPq for Excitotoxicity and Neuroprotection. We would like to thank the Laboratory of Neurochemistry and Cell Biology and the Postgraduate Program in Animal Science in the Tropics of the Federal University of Bahia for the support and CAPES for Master fellowships to VCMA (Process 0001). 


\section{Authors' contributions}

VCMA performed all experimentation, analyzed, interpreted the data and was a major contributor in writing the manuscript. MSOJ and $A B S$ helped with the maintenance of the cell culture and to perform RT-qPCR. JMD and JPD performed the chemical extraction of the flavonoid agathisflavone. MFDC, VDAS and AMB revised it critically for intellectual content. SLC supervised the study, edited and reviewed the manuscript. All authors read and approved the final manuscript.

\section{References}

Agra M de F, Silva KN, Basílio IJLD, et al (2008) Survey of medicinal plants used in the region Northeast of Brazil. Rev Bras Farmacogn 18:472-508. doi: 10.1590/S0102$695 \times 2008000300023$

Anderson MA, Burda JE, Ren Y, Ao Y, O'Shea TM, Kawaguchi R, Coppola G, Khakh BS, Deming TJ, Sofroniew MV. Astrocyte scar formation aids CNS axon regeneration. Nature. 2016 April 14; 532(7598): 195-200. doi:10.1038/nature17623

Armstrong RC, Mierzwa AJ, Sullivan GM, Sanchez MA (2016) Myelin and oligodendrocyte lineage cells in white matter pathology and plasticity after traumatic brain injury. Neuropharmacology 110:654-659. doi: 10.1016/j.neuropharm.2015.04.029

Bahia MV., Santos JB dos, David JP, David JM (2005) Biflavonoids and other phenolics from Caesalpinia pyramidalis (Fabaceae). J Braz Chem Soc 16:1402-1405. doi: $10.1590 /$ S0103-50532005000800017

Bahia MV, David JP, David JM. (2010) Occurrence of biflavones in leaves of Caesalpinia pyramidalis specimens. Quim. Nova 33 (2010), 1297-1300

Bankston AN, Mandler MD, Feng Y (2013) Oligodendroglia and neurotrophic factors in neurodegeneration. Neurosci Bull 29:216-228. doi: 10.1007/s12264-013-1321-3 
Barreto GE, Gonzalez J, Torres Y, Morales L (2011) Astrocytic-neuronal crosstalk: Implications for neuroprotection from brain injury. Neurosci Res 71:107-113. doi: 10.1016/j.neures.2011.06.004

Burda JE, Bernstein AM, Sofroniew M V. (2016) Astrocyte roles in traumatic brain injury. Exp Neurol 275:305-315. doi: 10.1016/j.expneurol.2015.03.020

Cepeda S, Sandoval M, Crescitelli M, et al (2020) The isoflavone genistein enhances osteoblastogenesis: signaling pathways involved. J Phys Bioche. doi: 10.1007/s13105-019-00722-3

Cherry JD, Olschowka JA, O'Banion M (2014) Neuroinflammation and M2 microglia: the good, the bad, and the inflamed. J Neuroinflammation 11:98. doi: 10.1186/17422094-11-98

Cohen AD, Zigmond MJ, Smith AD (2011) Effects of intrastriatal GDNF on the response of dopamine neurons to 6-hydroxydopamine: Time course of protection and neurorestoration. Brain Res 1370:80-88. doi: 10.1016/j.brainres.2010.11.006

Costa S, Planchenault T, Charriere-Bertrand C, et al (2002) Astroglial permissivity for neuritic outgrowth in neuron-astrocyte cocultures depends on regulation of laminin bioavailability. Glia 37:105-113. doi: 10.1002/glia.10015

de Sousa LRF, Wu H, Nebo L, et al (2015) Flavonoids as noncompetitive inhibitors of Dengue virus NS2B-NS3 protease: Inhibition kinetics and docking studies. Bioorg Med Chem 23:466-470. doi: 10.1016/j.bmc.2014.12.015

de Sousa LRF, Wu H, Nebo L, et al (2015) Natural products as inhibitors of recombinant cathepsin L of Leishmania mexicana. Exp Parasitol 156:42-48. doi: 10.1016/j.exppara.2015.05.016

Di Giovanni S, Movsesyan V, Ahmed F, et al (2005) Cell cycle inhibition provides neuroprotection and reduces glial proliferation and scar formation after traumatic 
brain injury. Proc Natl Acad Sci U S A 102:8333-8338. doi: 10.1073/pnas.0500989102

Diaz-Arrastia R, Kochanek PM, Bergold P, et al (2014) Pharmacotherapy of traumatic brain injury: state of the science and the road forward: report of the Department of Defense Neurotrauma Pharmacology Workgroup. J Neurotrauma 31:135-58. doi: 10.1089/neu.2013.3019

Diniz PBF, Ribeiro ARS, Estevam CS, et al (2015) Possible mechanisms of action of Caesalpinia pyramidalis against ethanol-induced gastric damage. J Ethnopharmacol 168:79-86. doi: 10.1016/j.jep.2015.03.054

dos Santos Souza C, Grangeiro MS, Lima Pereira EP, et al (2018) Agathisflavone, a flavonoid derived from Poincianella pyramidalis (Tul.), enhances neuronal population and protects against glutamate excitotoxicity. Neurotoxicology 65:85-97. doi: 10.1016/j.neuro.2018.02.001

Engler-Chiurazzi EB, Brown CM, Povroznik JM, Simpkins JW (2015) Estrogens as neuroprotectants: Estrogenic actions in the context of cognitive aging and brain injury. Prog. Neurobiol.

García-Lafuente A, Guillamón E, Villares A, et al (2009) Flavonoids as anti-inflammatory agents: Implications in cancer and cardiovascular disease. Inflamm Res 58:537552. doi: 10.1007/s00011-009-0037-3

Grosso C, Valentão P, Ferreres F, Andrade PB (2013) The use of flavonoids in central nervous system disorders. Curr Med Chem 20:4694-719. doi: $10.2174 / 09298673113209990155$

Han Z, Chen F, Ge X, et al (2014) MiR-21 alleviated apoptosis of cortical neurons through promoting PTEN-Akt signaling pathway in vitro after experimental traumatic brain injury. Brain Res 1582:12-20. doi: 10.1016/j.brainres.2014.07.045 
Helmy A, Antoniades CA, Guilfoyle MR, et al (2012) Principal Component Analysis of the Cytokine and Chemokine Response to Human Traumatic Brain Injury. PLoS One 7:e39677. doi: 10.1371/journal.pone.0039677

Huang T, Solano J, He D, et al (2009) Traumatic injury activates MAP kinases in astrocytes: mechanisms of hypothermia and hyperthermia. J Neurotrauma 26:1535-1545. doi: 10.1089/neu.2008-0743

Johnson VE, Stewart W, Smith DH (2013) Axonal pathology in traumatic brain injury. Exp Neurol 246:35-43. doi: 10.1016/j.expneurol.2012.01.013

Katano H, Fujita K, Kato T, et al (1999) Traumatic injury in vitro induces IEG mRNAs in cultured glial cells, suppressed by co-culture with neurons. Neuroreport 10:243948. doi: Doi 10.1097/00001756-199908200-00002

Kiyota T, Machhi J, Lu Y, et al (2018) URMC-099 facilitates amyloid- $\beta$ clearance in a murine model of Alzheimer's disease. J Neuroinflammation 15:137. doi: 10.1186/s12974-018-1172-y

Kobeissy FH, Liu MC, Yang Z, et al (2015) Degradation of Bll-Spectrin Protein by Calpain-2 and Caspase-3 Under Neurotoxic and Traumatic Brain Injury Conditions. Mol Neurobiol 52:696-709. doi: 10.1007/s12035-014-8898-z

Konan NA, Lincopan N, Collantes Díaz IE, et al (2012) Cytotoxicity of cashew flavonoids towards malignant cell lines. Exp Toxicol Pathol 64:435-440. doi: 10.1016/j.etp.2010.10.010

Kuipers SD, Trentani A, Tiron A, et al (2016) BDNF-induced LTP is associated with rapid Arc/Arg3.1-dependent enhancement in adult hippocampal neurogenesis. Sci Rep 6:21222. doi: 10.1038/srep21222

Lane JT (2014) The role of retinoids in the induction of nerve growth factor: a potential treatment for diabetic neuropathy. Transl Res 164:193-195. doi: 10.1016/j.trsl.2014.06.001 
Langlois, J. A., Rutland-Brown, W. \& Wald, M. M. The Epidemiology and Impact of Traumatic Brain Injury. J. Head Trauma Rehabil. 21, 375-378 (2006).

Lefrançois T, Fages C, Peschanski M, Tardy M (1997) Neuritic outgrowth associated with astroglial phenotypic changes induced by antisense glial fibrillary acidic protein (GFAP) mRNA in injured neuron-astrocyte cocultures. J Neurosci 17:4121-4128

Li R, Li Y, Wu Y, et al (2018) Heparin-Poloxamer Thermosensitive Hydrogel Loaded with bFGF and NGF Enhances Peripheral Nerve Regeneration in Diabetic Rats. Biomaterials 168:24-37. doi: 10.1016/j.biomaterials.2018.03.044

Lin Y-M, Anderson H, Flavin MT, et al (1997) In Vitro Anti-HIV Activity of Biflavonoids Isolated from Rhus succedanea and Garcinia multiflora. J Nat Prod 60:884-888. doi: $10.1021 / \mathrm{np} 9700275$

Loane DJ, Stoica BA, Tchantchou F, et al (2014) Novel mGluR5 Positive Allosteric Modulator Improves Functional Recovery, Attenuates Neurodegeneration, and Alters Microglial Polarization after Experimental Traumatic Brain Injury. Neurotherapeutics 11:857-869. doi: 10.1007/s13311-014-0298-6

Lööv C, Hillered L, Ebendal T, Erlandsson A (2012) Engulfing astrocytes protect neurons from contact-induced apoptosis following injury. PLoS One 7:. doi: 10.1371/journal.pone.0033090

Lööv C, Shevchenko G, Geeyarpuram Nadadhur A, et al (2013) Identification of Injury Specific Proteins in a Cell Culture Model of Traumatic Brain Injury. PLoS One 8:. doi: 10.1371/journal.pone.0055983

Luine VN (2014) Estradiol and cognitive function: Past, present and future. Horm Behav 66:602-618. doi: 10.1016/j.yhbeh.2014.08.011

Macready AL, George TW, Chong MF, et al (2014) Flavonoid-rich fruit and vegetables improve microvascular reactivity and inflammatory status in men at risk of 
cardiovascular disease - FLAVURS : a randomized controlled trial 1 - 5. Am J Clin Nutr 99:479-489. doi: 10.3945/ajcn.113.074237.Epidemiologic

Mendes, C. C., Bahia, M. V., David, J. M. and David, J. P. (2000) 'Constituents of Caesalpinia pyramidalis', Fitoterapia, 71(2), pp. 205-7.

Nagahara AH, Merrill DA, Coppola G, et al (2009) Neuroprotective effects of brainderived neurotrophic factor in rodent and primate models of Alzheimer's disease. Nat Med 15:331-337. doi: 10.1038/nm.1912

Paulsen BS, Souza CS, Chicaybam L, et al (2011) Agathisflavone Enhances Retinoic Acid-Induced Neurogenesis and Its Receptors $\alpha$ and $\beta$ in Pluripotent Stem Cells. Stem Cells Dev 20:1711-1721. doi: 10.1089/scd.2010.0446

Pekny M, Johansson CB, Eliasson C, et al (1999) Abnormal reaction to central nervous system injury in mice lacking glial fibrillary acidic protein and vimentin. J Cell Biol 145:503-514

Peluso I, Miglio C, Morabito G, et al (2015) Flavonoids and Immune Function in Human: A Systematic Review. Crit Rev Food Sci Nutr 55:383-395. doi: 10.1080/10408398.2012.656770

Rosenfeld J V., Maas Al, Bragge P, et al (2012) Early management of severe traumatic brain injury. Lancet 380:1088-1098. doi: 10.1016/S0140-6736(12)60864-2

Shi ZF, Zhao WJ, Xu LX, et al (2015) Downregulation of Aquaporin 4 Expression through Extracellular Signal-regulated Kinases1/2 Activation in Cultured Astrocytes Following Scratch-injury. Biomed Environ Sci 28:199-205. doi: $10.3967 /$ bes2015.026

Simon DW, McGeachy MJ, Bayır H, et al (2017) The far-reaching scope of neuroinflammation after traumatic brain injury. Nat Rev Neurol 13:171-191. doi: 10.1038/nrneurol.2017.13 
Su BY, Tung T, Chien W (2018) Effects of Phytoestrogens on Depressive Symptoms in Climacteric Women: A Meta-analysis of Randomized Controlled Trials. J Altern Complement Med 00:acm.2017.0118. doi: 10.1089/acm.2017.0118

Surgucheva I, He S, Rich MC, et al (2014) Role of synucleins in traumatic brain injury An experimental in vitro and in vivo study in mice. Mol Cell Neurosci 63:114-123. doi: 10.1016/j.mcn.2014.10.005

Taiwo BJ, Fatokun AA, Olubiyi OO, et al (2017) Identification of compounds with cytotoxic activity from the leaf of the Nigerian medicinal plant, Anacardium occidentale L. (Anacardiaceae). Bioorg Med Chem 25:2327-2335. doi: 10.1016/j.bmc.2017.02.040

Takeuchi K, Yang Y, Takayasu Y, et al (2015) Estradiol pretreatment ameliorates impaired synaptic plasticity at synapses of insulted CA1 neurons after transient global ischemia. Brain Res 1621:222-230. doi: 10.1016/j.brainres.2014.11.016

Thurman, D. J. The Epidemiology of Traumatic Brain Injury in Children and Youths. J. Child Neurol. 31, 20-27 (2016). https://doi.org/10.1177/0883073814544363

Velagapudi R, Ajileye OO, Okorji U, et al (2018) Agathisflavone isolated from Anacardium occidentale suppresses SIRT1-mediated neuroinflammation in BV2 microglia and neurotoxicity in APPSwe-transfected SH-SY5Y cells. Phyther Res 110. doi: $10.1002 /$ ptr.6122

Wanner IB, Anderson MA, Song B, et al (2013) Glial Scar Borders Are Formed by Newly Proliferated, Elongated Astrocytes That Interact to Corral Inflammatory and Fibrotic Cells via STAT3-Dependent Mechanisms after Spinal Cord Injury. J Neurosci 33:12870-12886. doi: 10.1523/JNEUROSCI.2121-13.2013

Weber JT, Lamont M, Chibrikova L, et al (2012) Potential neuroprotective effects of oxyresveratrol against traumatic injury. Eur J Pharmacol 680:55-62. doi: 10.1016/j.ejphar.2012.01.036 
Wu L, Zhang QL, Zhang XY, et al (2012) Pharmacokinetics and blood-brain barrier penetration of $(+)$-Catechin and (-)-Epicatechin in rats by microdialysis sampling coupled to high-performance liquid chromatography with chemiluminescence detection. J Agric Food Chem 60:9377-9383. doi: 10.1021/jf301787f

Wurzelmann M, Romeika J, Sun D (2017) Therapeutic potential of brain-derived neurotrophic factor (BDNF) and a small molecular mimics of BDNF for traumatic brain injury. Neural Regen Res 12:7. doi: 10.4103/1673-5374.198964

Zand RSR, Jenkins DJA, Diamandis EP (2000) Steroid hormone activity of flavonoids and related compounds. Breast Cancer Res Treat 62:35-49. doi: 10.1023/A:1006422302173

Zhang H, Tsao R (2016) Dietary polyphenols, oxidative stress and antioxidant and antiinflammatory effects. Curr Opin Food Sci 8:33-42. doi: 10.1016/j.cofs.2016.02.002

Zhang Y, Feng S, Nie K, et al (2018) TREM2 modulates microglia phenotypes in the neuroinflammation of Parkinson's disease. Biochem Biophys Res Commun 499:797-802. doi: 10.1016/j.bbrc.2018.03.226 